\title{
Nondestructive Measurement of Water Content and Moisture Migration of Unsaturated Red Clays in South China
}

\author{
Junhui Zhang, ${ }^{1}$ Qingping Jiang, ${ }^{1}$ Yuqing Zhang, ${ }^{2}$ Liangliang Dai, ${ }^{1}$ and Houxuan Wu ${ }^{3}$ \\ ${ }^{1}$ School of Traffic and Transportation Engineering, Changsha University of Science \& Technology, Changsha 410114, China \\ ${ }^{2}$ School of Engineering and Applied Science, Aston University, Birmingham B4 7ET, UK \\ ${ }^{3}$ Jiangxi Ganyue Expressway Co. Ltd, Nanchang 330029, China
}

Correspondence should be addressed to Junhui Zhang; zjhseu@163.com

Received 29 May 2015; Accepted 19 October 2015

Academic Editor: Hiroshi Noguchi

Copyright (C) 2015 Junhui Zhang et al. This is an open access article distributed under the Creative Commons Attribution License, which permits unrestricted use, distribution, and reproduction in any medium, provided the original work is properly cited.

\begin{abstract}
To reveal the moisture migration mechanism of the unsaturated red clays, which are sensitive to water content change and widely distributed in South China, and then rationally use them as a filling material for highway embankments, a method to measure the water content of red clay cylinders using X-ray computed tomography (CT) was proposed and verified. Then, studies on the moisture migrations in the red clays under the rainfall and ground water level were performed at different degrees of compaction. The results show that the relationship between dry density, water content, and CT value determined from X-ray CT tests can be used to nondestructively measure the water content of red clay cylinders at different migration time, which avoids the error reduced by the sample-to-sample variation. The rainfall, ground water level, and degree of compaction are factors that can significantly affect the moisture migration distance and migration rate. Some techniques, such as lowering groundwater table and increasing degree of compaction of the red clays, can be used to prevent or delay the moisture migration in highway embankments filled with red clays.
\end{abstract}

\section{Introduction}

Red clays are widely distributed in South China, which are unsaturated and highly sensitive to moisture change. With the rapid increase of the highway constructions, many highways are being built on the red clay subgrade. The existing subgrade treatment methods of replacing the red clays with high quality filling materials have tended to be unacceptable due to the increasing consciousness of the environmental protection and natural resource conservation. Accordingly, using the red clays as a construction material of highways becomes economically attractive, whereas the characteristic of red clays mentioned above makes its application to highway construction become a major issue [1].

Since the red clays are moisture dependent, when the water content is different from the surrounding conditions, the moisture migration will happen sharply due to the water potential [2]. Zhou [3] found that the design value of water content of the red clays as a filling material of the highway embankment is much lower than the equilibrium water content of the red clays in South China, which significantly relies on the local climate conditions. Thus, the water content in the embankment will gradually approach the equilibrium moisture content after construction, and, eventually, the moisture migration results in a reduction of the soil shear strength, a loss of the structural bearing capacity, and a continuous increase of permanent deformation of the subgrade [4-6]. This causes numerous road distresses, especially the slope collapse. Therefore, understanding the moisture migration mechanism of the unsaturated red clays is important for engineers, which can provide the methods to prevent the moisture migration and decrease the distresses of moisture-induced landslides.

Studies of the moisture migration in soils have been performed based on the soil water potential concept. There are many methods to investigate the moisture migration, such as laboratory experiments [4], field tests [7], numerical simulations [8], and analytical methods [9]. Laboratory experiments 
using soil cylinders were heavily used to study the moisture migration considering the relatively low equipment requirements and easily controlled boundary conditions $[4,10]$. Researchers investigated the moisture migration mechanism by determining the water content of the soil cylinders at different migration time under different boundary conditions. Up to present, the methods to measure the water content of a soil specimen in the laboratory include oven drying method, electric resistivity method [11], neutron method [12], gammaray method [13], and time domain reflectometry (TDR) method [14]. However, oven drying, electric resistivity, and TDR methods measure one water content for one specimen. To obtain the moisture content at different migration time, multiple soil cylinders are needed. Therefore, sample-to-sample variation becomes an issue in the accurate determination of the moisture migration. Neutron and gamma-ray methods are capable of measuring the water content of soil cylinders in a nondestructive and continuous manner, but the accuracy and safety of the tests are still concerned. Currently, many studies have used X-ray computed tomography (CT), which is a relatively safe research method with a satisfactory accuracy, for nondestructive quality evaluation and for understanding the failure mechanisms according to the attenuation amount of the X-ray while producing much less radiation than the neutron and gamma-ray methods. However, the existing applications of X-ray CT were mainly focused on the internal structure of soil and bituminous mixture [15]. Limited studies were found to determine the water content of red clays.

The objectives of this paper are to develop a nondestructive method to measure the water content of the red clays using $\mathrm{X}$-ray CT and to investigate the mechanisms of the moisture migration in the red clays by monitoring the moisture content at different migration time using this nondestructive method. The paper is organized as follows. The forthcoming section introduces the procedures of X-ray CT scanning tests of red clay cylinders with three different degrees of compaction at $90 \%, 93 \%$, and $96 \%$. The relationship among the dry density, water content, and the CT value is proposed and validated. After that, the influential factors of the moisture migration are evaluated. The moisture migration tests are performed on the soil cylinders with the optimum water content of $12.9 \%$ at different conditions including degree of compaction, ground water, and rainfall. The soil cylinders at different migration time are scanned using X-ray CT and their water contents are calculated using the correlation among the dry density, water content, and the CT value developed in the previous section. In the following, the effects of the rainfall, ground water, migration time, and degree of compaction on the moisture migration of the red clay cylinders are evaluated. The final section summarizes the major findings of this study.

\section{Nondestructive Measurement of Water Content of Red Clay Cylinders Using X-Ray CT}

2.1. Materials. The soil samples were taken from the field site of Nanchang-Zhangshu highway widening project in Jiangxi
Province. Their natural water content is $18.2 \%$; the liquid limit and plastic limit are $44 \%$ and $22 \%$, respectively. According to the compaction test, the optimum water content and maximum dry density are $12.9 \%$ and $1.949 \mathrm{~g} / \mathrm{cm}^{3}$, respectively. Particle size analysis shows that the $0.075 \mathrm{~mm}$ passing percentage of the soil samples is $78 \%$. So, the soil sample was categorized as low liquid-limit clay (CL) according to the standard of Test Methods of Soils for Highway Engineering (JTG E40-2007) in China.

2.2. Sample Preparation. According to the specification of the degree of compaction of an embankment in China, the target degree of compaction of the soil cylinders is $96 \%, 93 \%$, and $90 \%$, with corresponding target density of $1.871 \mathrm{~g} / \mathrm{cm}^{3}$, $1.812 \mathrm{~g} / \mathrm{cm}^{3}$, and $1.754 \mathrm{~g} / \mathrm{cm}^{3}$, respectively. When molded, the target water contents of the cylinders include $0 \%, 3 \%, 6 \%, 9 \%$, and $12 \%$ at each degree of compaction.

In order to fabricate soil cylinders at the target degree of compaction and water content, a laboratory designed splitting mold with a diameter of $7.2 \mathrm{~cm}$ and a length of $7.0 \mathrm{~cm}$ was used. The cylinders were divided into five layers for molding. After filling each layer, it was compacted using a metal bar to achieve an initial degree of compaction, and then the next layer was filled and compacted till all the layers were finished. Subsequently, the completed soil cylinder was compacted until the designed height was reached, which corresponds to the designed degree of compaction. It was found that the soil cylinders with the water content below $6 \%$ were unable to be demolded. Therefore, the columns molded at the water content of $6 \%$ were dried in an oven at $30^{\circ} \mathrm{C}$ and weighted until the target water content was reached. After that, the cylinders were sealed for 15 days, before the X-ray CT scanning, and rotated by $60^{\circ}$ every two days to ensure that the water was fully balanced. To verify the uniform distribution of the moisture in the soil cylinder, the conditioned cylinder was cut into three slices and the moisture content along the length was measured at three different locations of each slice. It was observed that the water content of the soil cylinder was uniformly distributed in the sample and the average water content was close to the molding moisture content.

\subsection{Involved CT System and CT Scanning Test. Figure 1(a)} shows the schematic diagram of an industry CT system. When the X-ray penetrates the soil cylinder, the attenuation of an X-ray is measured by the detector. In order to reflect this attenuation amount, a term of CT value symbolized by $H U$ was introduced, which was first proposed by Hounsfield and then was widely used [16]. It can be read directly using the postprocessing software in the CT system. Soil generally consists of soil particles, water, and air. The attenuation of Xray of air is zero. Therefore, red clay cylinders have different attenuation amount of the X-ray when the water content and dry density are different. Thus, a correlation exists among the water content, dry density of a red clay cylinder, and the attenuation amount of X-ray. In order to investigate this correlation, the $\mathrm{X}$-ray $\mathrm{CT}$ scanning tests of red clay cylinders were conducted. The X-ray CT system (manufactured by XYLON of Germany, model MG325) in Changsha University 


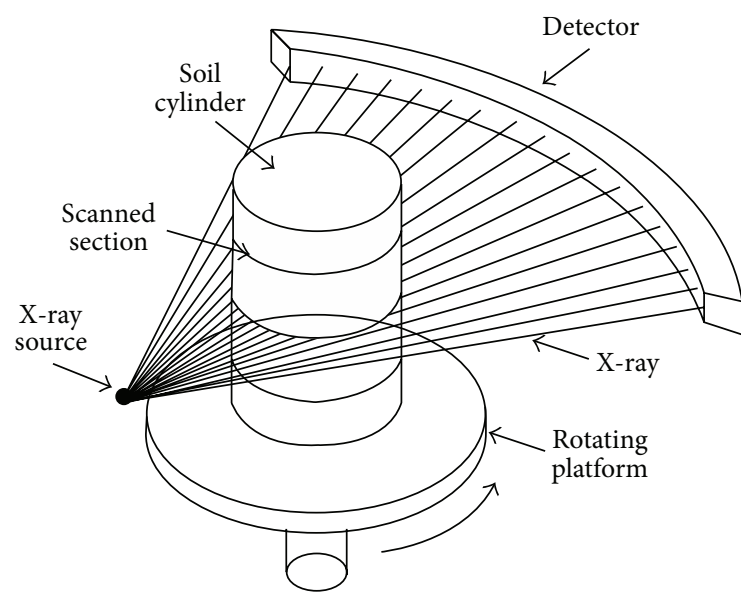

(a) X-ray CT scanning configuration

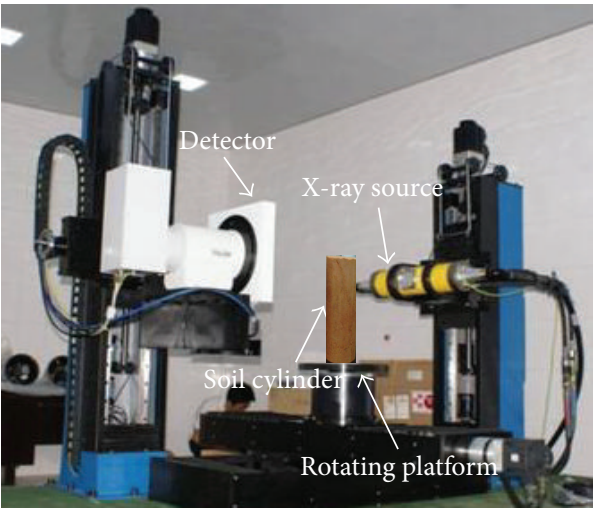

(b) X-ray CT test set-up

Figure 1: Configuration of X-ray CT scanning test.

of Science \& Technology was used. The energy parameters of the X-ray are $250 \mathrm{KV}$ in voltage, $2.0 \mathrm{~mA}$ in current, and $1.9 \mathrm{~mm}$ in magnitude focus. A total of 3 layers were scanned for each specimen, as shown in Figure 1(b).

2.4. Relationship between Dry Density, Water Content, and CT Value. Based on the measured average CT value of the scanned sections, a correlation was established between the water content and the CT value which is a linear relationship as shown in Figure 2. The linear relationship is relatively weak $\left(R^{2}=0.963\right)$ for the red clays at the compaction degree of $96 \%$. This is due to the fact that the dry density of the molded specimens with water content of $11.46 \%$ and $5.22 \%$ was $1.881 \mathrm{~g} / \mathrm{cm}^{3}$ and $1.858 \mathrm{~g} / \mathrm{cm}^{3}$, respectively, which was different from the target dry density $\left(1.871 \mathrm{~g} / \mathrm{cm}^{3}\right)$.

To comprehensively consider the effects of the dry density and water content on the CT value, a correlation between CT value, water content, and dry density for the red clays was built as follows:

$$
H U=2.695 \rho_{d}+0.018 \rho_{d} w-0.225 \quad\left(R^{2}=0.991\right),
$$

where $H U$ is the CT value and $\rho_{d}$ and $w$ are the dry density and water content of red clay cylinders.

In order to validate the relationship in (1), red clay cylinders with three specific dry densities at random water contents were fabricated and scanned using X-ray CT. The average $\mathrm{CT}$ value of three scanned sections for each specimen was determined, which was used in (1) to back-calculate the water content together with the target dry density. Table 1 compares the calculated and measured water content using the oven drying method for each specimen. It is found from Table 1 that the calculated values agreed fairly well with the measured water contents. This indicates the established correlation of the water content and dry density to the CT value is reliable.

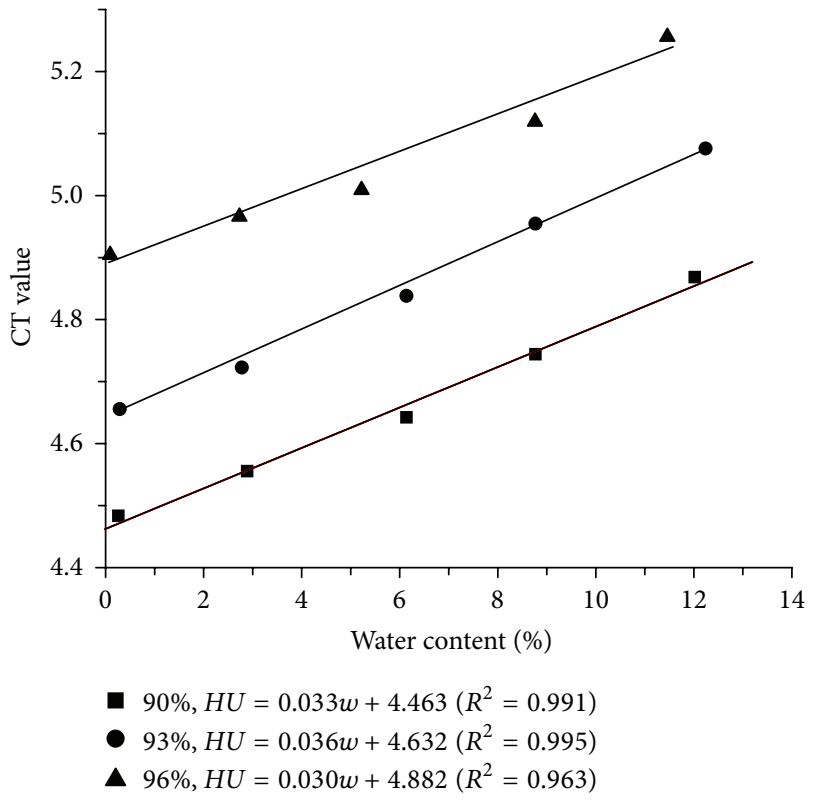

FIGURE 2: Relationship between water content and CT value at different degrees of compaction.

\section{Tests and Analysis of Moisture Migration}

To investigate the moisture migration in red clays, moisture migration tests were developed and the water content at different migration time was monitored using X-ray CT scanning test and the relationship in (1).

3.1. Moisture Migration Test Configuration. To address the precipitation and capillary action in South China, rainfall and ground water level were simulated, which are depicted as follows.

According to the precipitation record in South China, a moderate rainfall of $3.5 \mathrm{~mm} / \mathrm{h}$ was selected. Figure 3 presents 
TABLE 1: Validation of the relationship between water content, dry density, and CT value.

\begin{tabular}{lcccc}
\hline CT value & Dry density $/\left(\mathrm{g} / \mathrm{cm}^{3}\right)$ & Calculated water content $/ \%$ & Measured water content/\% & Difference value/\% \\
\hline 4.744 & 1.720 & 10.55 & 10.1 & -0.45 \\
5.073 & 1.855 & 8.750 & 9.1 & 0.35 \\
5.110 & 1.788 & 15.71 & 16.25 & 0.54 \\
\hline
\end{tabular}

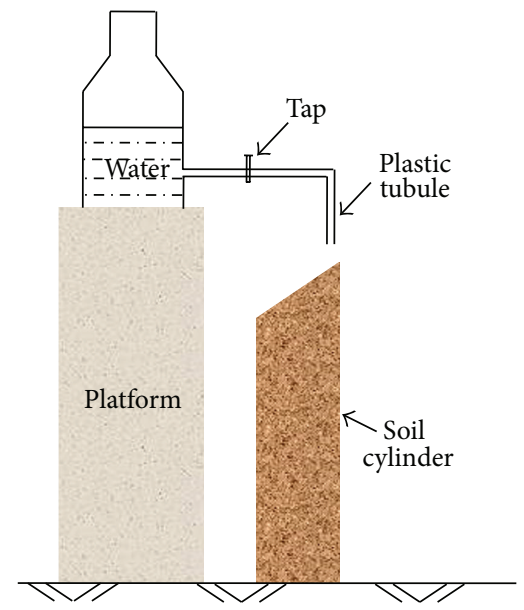

(a) Schematic model

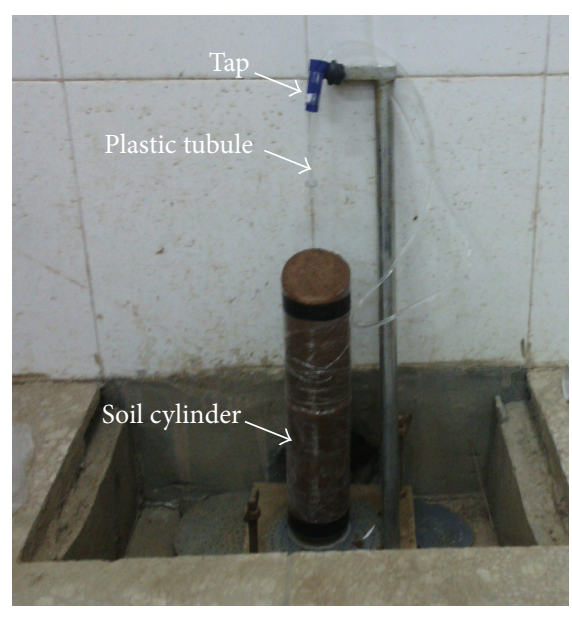

(b) Experimental apparatus

FIGURE 3: Rainfall simulation test on red clay cylinder specimen.

the schematic model and the experimental apparatus. As shown in Figure 3, a plastic tubule and a tap were used to simulate the rainfall, which were close to the top of the soil cylinder to prevent eroding its surface; the top of the soil cylinder was cut with a slope of 1:1.75 to simulate the effect of rainfall on the subgrade slope. The rainfall intensity was achieved by continually adjusting the water flow of the tap. In order to match the target rainfall of $3.5 \mathrm{~mm} / \mathrm{h}$, the water with an intensity of $16.4 \mathrm{~g} / \mathrm{h}$ should fall on the inclined ellipse surface of the red clay cylinder.

In order to simulate the ground water level below the red clay subgrade, the cylinder specimens were put in a glass box filled with fine sands, which were saturated, as shown in Figure 4. The top and lateral surface of the soil cylinder was sealed using a plastic cap and wrap during the test to avoid evaporation, as shown in Figure 4(b).

The soil cylinders with the heights of $30 \mathrm{~cm}$ and $45 \mathrm{~cm}$ for the rainfall and ground water level simulation tests were fabricated using the same molding method presented in the previous section. After this, the soil cylinders were sealed for 15 days and rotated $60^{\circ}$ every two days to balance their moisture content. At different migration time, the soil cylinders were scanned using the X-ray CT system mentioned above for every $2 \mathrm{~cm}$ height and water contents were calculated using (1). In order to evaluate the effect of the degree of compaction on moisture migration, red clay cylinders with three degrees of compaction of $90 \%, 93 \%$, and $96 \%$ were molded in the rainfall simulation tests. All the soil cylinders were molded under the optimum water content of $12.9 \%$. In addition, the moisture migration at different time was investigated. Table 2 shows the detailed testing parameters in the three simulation tests.

3.2. Effect of Rainfall on Moisture Migration. Figure 5 shows the moisture content distributions after different migration time in the rainfall simulation tests. It is observed from Figure 5(a) that the water content increases from the bottom to the top of the clay cylinder. To quantify the moisture migration in the red clay cylinder, a wetting front was defined as the distance from the water source (the specimen top) to a height where the water content starts to increase at a specific migration time. Figure 5(a) indicates that, below the wetting front, the sample water content remains unchanged at a basic value around $13 \%$. Figure 5(a) also shows that the wetting front increases (moves downward) with the increase of the migration time. When the moisture migration lasted 12 hours, 24 hours, and 48 hours, the wetting front moved downward from the soil cylinder top for about $14 \mathrm{~cm}, 18 \mathrm{~cm}$, and $24 \mathrm{~cm}$, respectively. Figure 5(b) shows the sectional water content at different height of the specimen versus migration time. It is found that the upper part $(>26 \mathrm{~cm})$ of the cylinder sample has a high water content, and the lower part $(<10 \mathrm{~cm})$ has a relatively low water content. The middle part (between $12 \mathrm{~cm}$ and $22 \mathrm{~cm}$ ) has an increasing water content with the migration time, which indicates the downward moving of the wetting front when the soil cylinder is subjected to a constant rainfall.

3.3. Effect of Ground Water Level on Moisture Migration. Moisture contents at different migration time in ground water 
TABLE 2: Details of test parameters.

\begin{tabular}{lcccc}
\hline Factors & Variable & Height of cylinders $/ \mathrm{cm}$ & Degree of compaction/\% & Time \\
\hline Rainfall & Intensity of $3.5 \mathrm{~mm} / \mathrm{h} @ 25^{\circ} \mathrm{C}$ & 30 & $90,93,96$ & $12 \mathrm{~h}, 24 \mathrm{~h}, 48 \mathrm{~h}$ \\
Ground water & $@ 25^{\circ} \mathrm{C}$ & 45 & 93 & $1 \mathrm{~d}, 3 \mathrm{~d}, 7 \mathrm{~d}$ \\
\hline
\end{tabular}

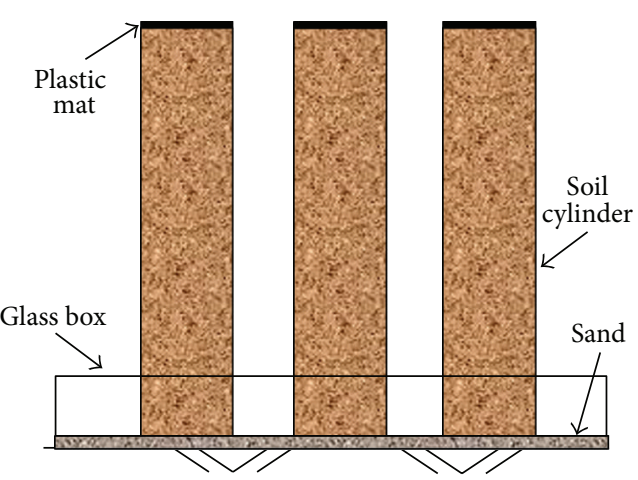

(a) Schematic model

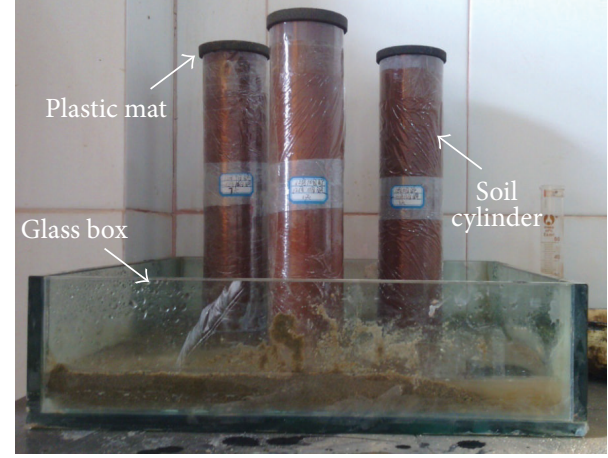

(b) Experimental apparatus

FIGURE 4: Ground water simulation tests on red clay cylinder specimen.

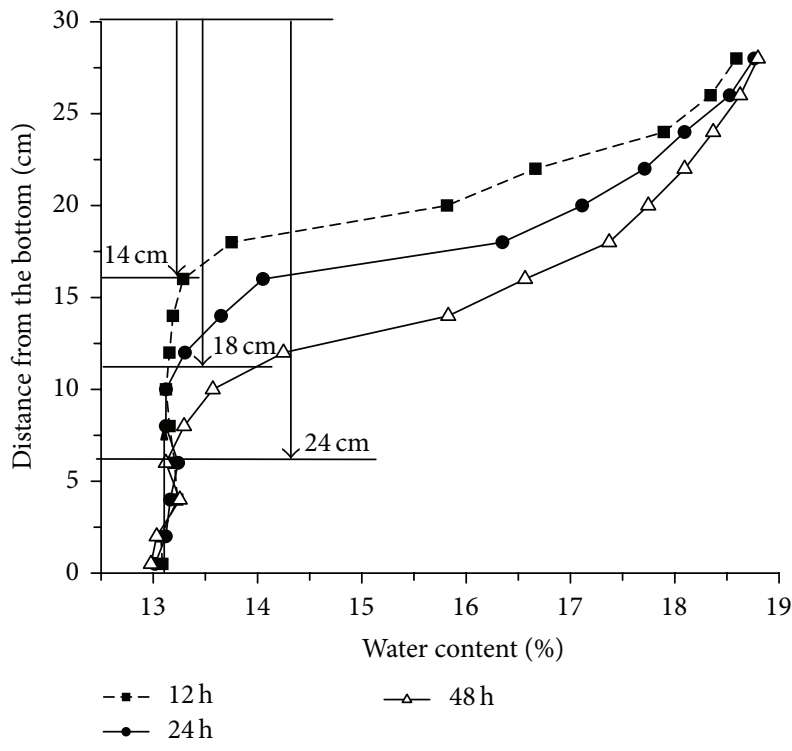

(a) Moisture along the length of soil cylinder

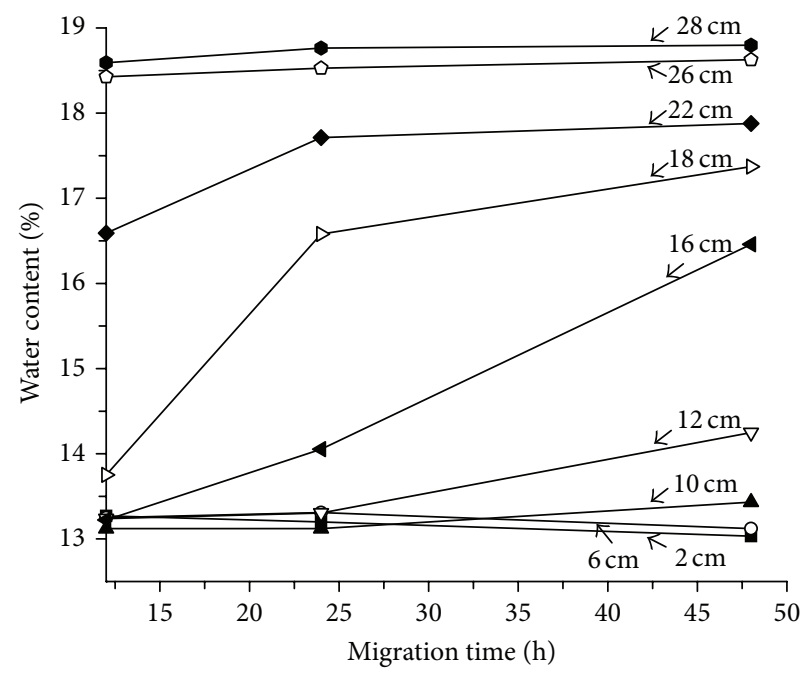

(b) Sectional moisture content

FIGURE 5: Distribution of water content in the rainfall simulation test.

level simulation test are shown in Figure 6. It is seen that the longer the migration time the higher the wetting front which is defined as the distance from the water source (bottom of the specimen immerged in the water of the glass box) to the height where the water content starts to grow. Figure 6(a) shows that when the moisture migration lasts 1 day, 3 days, and 7 days, wetting front of the soil cylinders reaches $12 \mathrm{~cm}$, $26 \mathrm{~cm}$, and $38 \mathrm{~cm}$, respectively. The sectional water contents at different height of the specimen are shown in Figure 6(b). Moreover, since gravitational potential and moisture migration have an opposite direction, the moving rate of the wetting front decreased with the growth of migration time. Therefore, as shown in Figure 6(b), the moisture migration took 1 day, 2 days, and 4 days to reach the height of $12 \mathrm{~cm}, 26 \mathrm{~cm}$, and $38 \mathrm{~cm}$, respectively.

3.4. Effect of the Degree of Compaction on Moisture Migration. In order to investigate the effect of the degree of compaction on the distribution of water content in the red clay cylinders, Figure 7 shows the moisture migration rate of the soil cylinders at different degrees of compaction used in the rainfall simulation tests. The moisture migration rate is defined as 


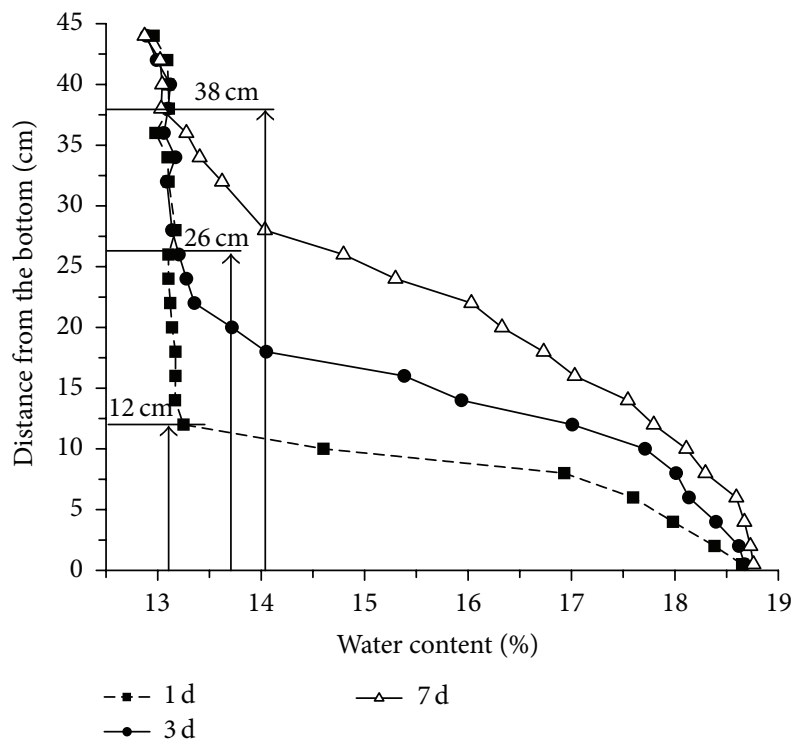

(a) Moisture along the length of soil cylinder

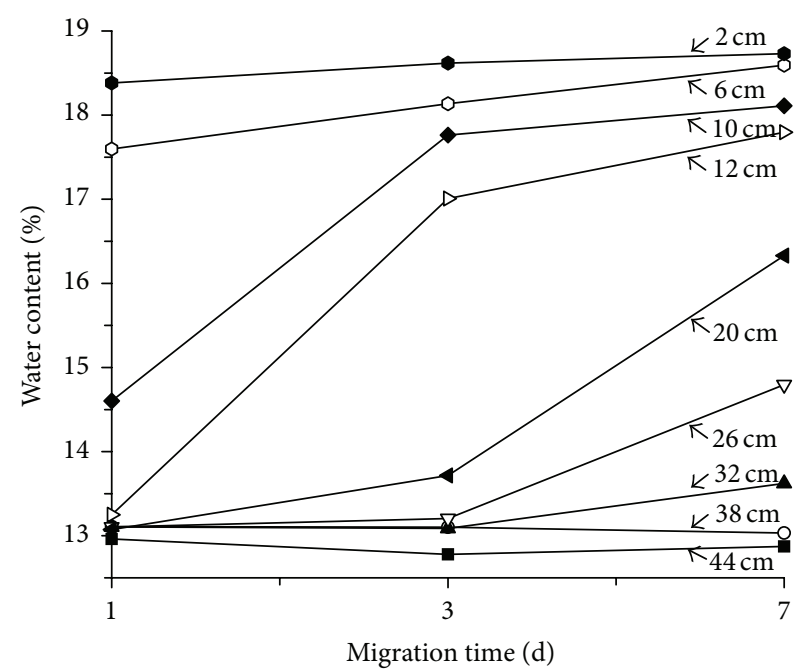

(b) Sectional moisture content

FIgURE 6: Distribution of water content in the ground water level simulation tests.

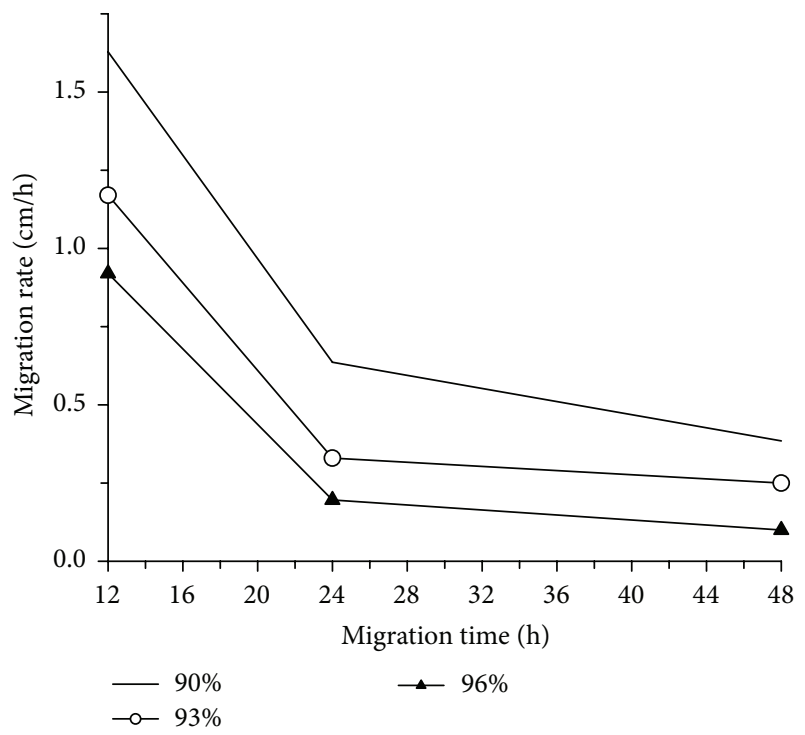

FIGURE 7: Migration rate of rainfall test with different compaction degrees.

the travel distance of the wetting front through the height of the clay cylinder per hour. It is seen from Figure 7 that the moisture migration rate decreases with the increase of the degree of compaction at the same migration time. With the elapse of the migration time, the moisture migration rate is reduced at a specific degree of compaction. This is because of the fact that the voids embedded in the soil particles are compressed and squeezed with the increase of the degree of compaction; therefore the channels for the moisture migration are reduced and become narrow. In order to achieve a stable and equilibrial moisture condition, moisture migration can be slowed down by increasing the compaction degree of the red clays or by providing sufficient moisture migration time.

\section{Conclusions and Discussions}

The measurement of moisture content in an unsaturated red clay cylinder was studied using X-ray CT tests and the moisture migration simulation tests at rainfall and ground water level. Some major conclusions may be drawn as follows:

(1) A relationship was developed and validated among the X-ray CT value, water content, and dry density for the red clays. Based on this relationship, one specimen is sufficient to determine the water content at different migration time. The efficiency of moisture migration tests is significantly improved and the sample-tosample variations are greatly reduced.

(2) Rainfall density, ground water level, and degrees of compaction have significant influence on the moisture migration in the red clays. With the elapse of the migration time, the moisture diffuses to a further distance. With the increase of the degree of compaction, the channels for moisture migration become narrow and the moisture migration rate decreases.

(3) According to the test results, some construction methods, such as lowering ground water table and increasing degree of compaction of the red clays, can be used to reduce or avoid the distresses, such as slope collapse and pavement cracks, resulting from moisture migration of the red clays.

(4) The effect of ground water level and rainfall on the moisture migration was studied separately and only one-dimensional model tests were conducted in this study. Actually, the moisture migration in embankment is a three-dimensional problem, which is affected by ground water level and rainfall simultaneously. Therefore, their combined influence on the 
moisture migration should be analyzed further and a three-dimensional model test should be also used.

\section{Conflict of Interests}

The authors declare that there is no conflict of interests regarding the publication of this paper.

\section{Acknowledgments}

The authors acknowledge the National High Technology Research and Development Program of China (2012AA112504), National Natural Science Foundation of China (51108048 and 51478054), and Jiangxi Communications Department Program (2013C0011) for the financial support. The authors also gratefully acknowledge the financial support from China Scholarship Council.

\section{References}

[1] X.-F. Hu, J. Wei, Y. Du et al., "Regional distribution of the Quaternary Red Clay with aeolian dust characteristics in subtropical China and its paleoclimatic implications," Geoderma, vol. 159, no. 3-4, pp. 317-334, 2010.

[2] B. D’Angelo, A. Bruand, J. T. Qin et al., "Origin of the high sensitivity of Chinese red clay soils to drought: significance of the clay characteristics," Geoderma, vol. 223-225, no. 1, pp. 4653, 2014.

[3] Y.Zhou, Research on subgrade moisture distribution and stiffness of humidity dependence in hot and humid areas [M.S. thesis], Changsha University of Science \& Technology, Changsha, China, 2014 (Chinese).

[4] F. Masrouri, K. V. Bicalho, and K. Kawai, "Laboratory hydraulic testing in unsaturated soils," Geotechnical and Geological Engineering, vol. 26, no. 6, pp. 691-704, 2008.

[5] F. Gu, H. Sahin, X. Luo, R. Luo, and R. L. Lytton, "Estimation of resilient modulus of unbound aggregates using performancerelated base course properties," Journal of Materials in Civil Engineering, vol. 27, no. 6, Article ID 04014188, 2015.

[6] H. Sahin, F. Gu, and R. L. Lytton, "Development of soilwater characteristic curve for flexible base materials using the methylene blue test," Journal of Materials in Civil Engineering, vol. 27, no. 5, Article ID 04014175, 2015.

[7] Q.-B. Bui, J.-C. Morel, S. Hans, and P. Walker, "Effect of moisture content on the mechanical characteristics of rammed earth," Construction and Building Materials, vol. 54, pp. 163-169, 2014.

[8] L. Guo, W. A. Jury, and W. T. Frankenberger Jr., "Coupled production and transport of selenium vapor in unsaturated soil: evaluation by experiments and numerical simulation," Journal of Contaminant Hydrology, vol. 49, no. 1-2, pp. 67-85, 2001.

[9] E. Zehe, T. Maurer, J. Ihringer, and E. Plate, "Modeling water flow and mass transport in a loess catchment," Physics and Chemistry of the Earth, Part B: Hydrology, Oceans and Atmosphere, vol. 26, no. 7-8, pp. 487-507, 2001.

[10] M. W. Wang, J. Li, S. Ge, and S. T. Li, "Moisture migration tests on unsaturated expansive clays in Hefei, China," Applied Clay Science, vol. 79, pp. 30-35, 2013.

[11] M. S. Seyfried, "Field calibration and monitoring of soil-water content with fiberglass electrical resistance sensors," Soil Science Society of America Journal, vol. 57, no. 6, pp. 1432-1436, 1993.
[12] S. Fityus, T. Wells, and W. Huang, "Water content measurement in expansive soils using the neutron probe," Geotechnical Testing Journal, vol. 34, no. 3, pp. 255-264, 2011.

[13] L. F. Pires, O. O. S. Bacchi, and K. Reichardt, "Soil water retention curve determined by gamma-ray beam attenuation," Soil and Tillage Research, vol. 82, no. 1, pp. 89-97, 2005.

[14] R. P. Chen, Y. M. Chen, W. Xu, and X. Yu, "Measurement of electrical conductivity of pore water in saturated sandy soils using time domain reflectometry (TDR) measurements," Canadian Geotechnical Journal, vol. 47, no. 2, pp. 197-206, 2010.

[15] R. L. Peyton, C. J. Gantzer, S. H. Anderson, B. A. Haeffner, and P. Pfeifer, "Fractal dimension to describe soil macropore structure using X-ray computed tomography," Water Resources Research, vol. 30, no. 3, pp. 691-700, 1994.

[16] C. David, B. Nöhammer, H. H. Solak, and E. Ziegler, "Differential X-ray phase contrast imaging using a shearing interferometer," Applied Physics Letters, vol. 81, no. 17, pp. 3287-3289, 2002. 

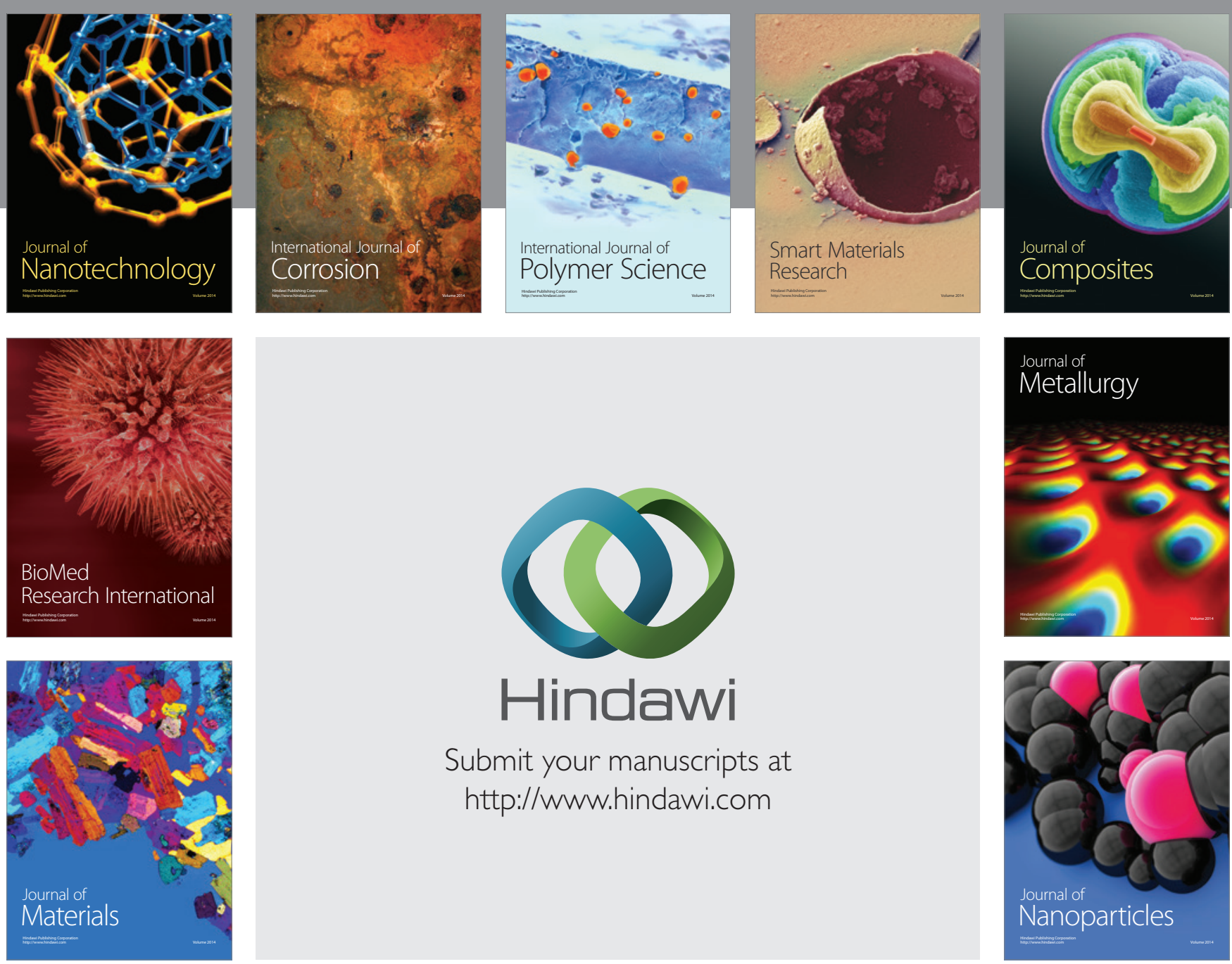

Submit your manuscripts at http://www.hindawi.com
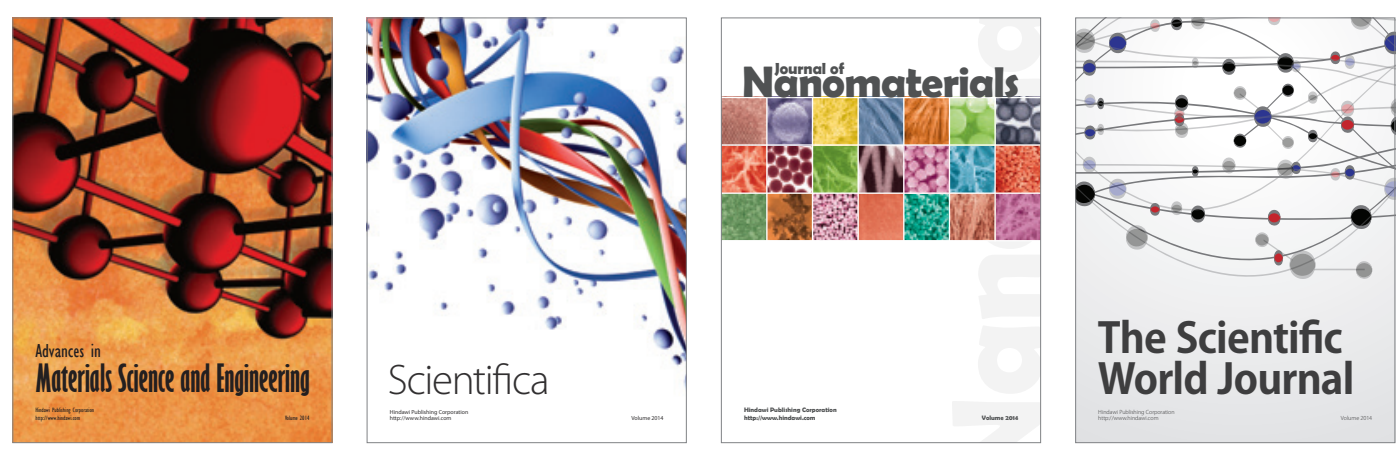

\section{The Scientific World Journal}
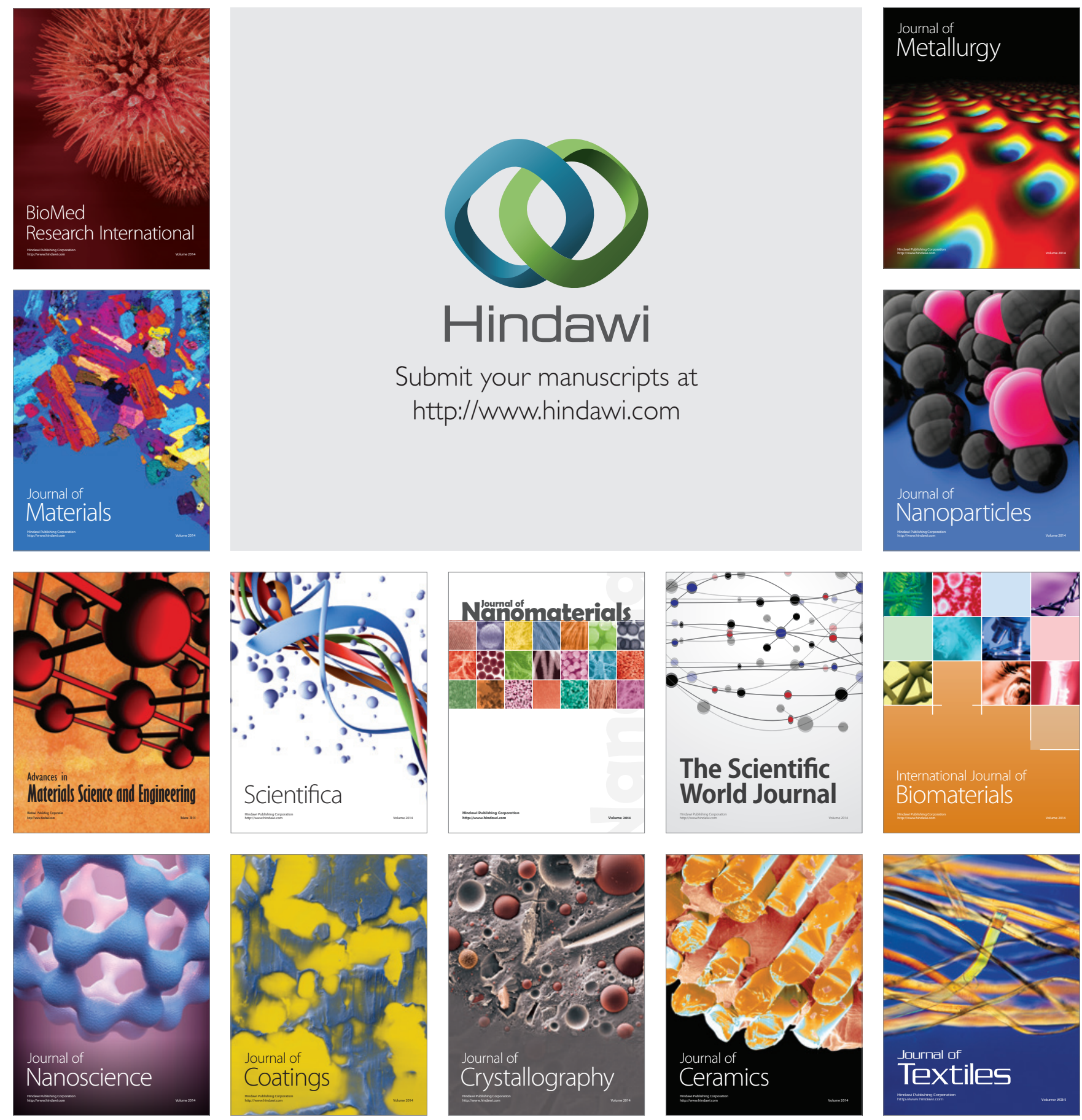